Krisztina Polgárdi*

\title{
Typology of weak disharmony: representations versus the frontness/ backness scale
}

DOI 10.1515/tl-2015-0005

\section{Introduction}

Rebrus and Törkenczy (this volume) (henceforth R\&T) propose a very interesting account of the typology of neutral vowel behaviour on the basis of a so-called frontness/backness scale. In their analysis, they simply assume that neutral vowels in palatal harmony systems are front, without utilising this information, although they acknowledge the existence of a body of literature that derives the typology from the quality (i.e. representation) of neutral vowels. In this commentary, I consider one concrete instantiation of such a representational approach and compare its typological predictions with those of the theory employing the frontness/backness scale.

The framework adopted is that of Government Phonology (GP) (Kaye et al. 1985, Kaye et al. 1990; Harris 1994, etc.), which employs the three privative elements I, A and $\mathbf{U}$ for the representation of vowels. The behaviour of neutral vowels as transparent or opaque was proposed to be predictable from their segmental make-up by Van der Hulst and Smith (1986), developed further by Van der Hulst (1988), Demirdache (1988), Dienes (1997, 2000) and Polgárdi (1998), among others. The basic insight is that neutral vowels possessing the harmonic feature are expected to be transparent because the harmonic feature is compatible with them and can spread through them, while neutral vowels lacking the harmonic feature are expected to be opaque because they block spreading due to their incompatibility with the harmonic feature (and they cannot be skipped either because of the principle of locality). Furthermore, transparent and harmonic vowels are distinguished by the status of the harmonic feature they contain: in a transparent vowel it constitutes the head, while in a harmonic vowel it is an operator. Operators, being more loosely connected to the core of the segment, may spread, whereas heads may not, or only under

*Corresponding author: Krisztina Polgárdi, Research Institute for Linguistics, Hungarian Academy of Sciences, Benczúr u. 33., 1068 Budapest, Hungary, E-mail: polgardi.krisztina@nytud.mta.hu 
special circumstances (defined below). In addition, "idiosyncratic transparency" of neutral vowels without the harmonic feature is allowed if the neutral vowel can be argued to be completely empty, while "idiosyncratic opacity" of neutral vowels with the harmonic feature is possible if harmony is parasitic on an element the vowel in question lacks.

Before examining the typological consequences, let us first review an analysis of Hungarian transparent vowels in this approach.

\section{Hungarian transparent vowels}

Dienes (1997, 2000) analyses the Hungarian vowel system as given in (1). I in this system stands for palatality, $\mathbf{U}$ for rounding and $\mathbf{A}$ for openness. Headedness, indicated by underlining, stands for preponderance of a particular element within a melodic expression. Headless expressions are also licit.

(1) Hungarian vowel system

(a) short vowels

$$
\begin{aligned}
& \text { i [i] I } \quad \ddot{\mathrm{u}}[\mathrm{y}] \text { I. } \underline{\mathbf{U}} \quad \mathrm{u}[\mathrm{u}] \underline{\mathbf{U}} \\
& \text { ö [ø] AI.U o [o] A.U } \\
& \text { e [ع] AI. a [ग] A. }
\end{aligned}
$$

(b) long vowels

$$
\begin{array}{lll}
\text { í [i:] I } & \text { ü [y:] I.U } & \text { ú [u:] } \underline{\mathbf{U}} \\
\text { é [e:] A.I } & \text { ô [ø:] AI. } \underline{\mathbf{U}} & \text { ó [o:] } \mathbf{A} . \underline{\mathbf{U}}
\end{array}
$$

á [a:] $\underline{\mathbf{A}}$

Hungarian exhibits palatal harmony (and a restricted version of labial harmony,

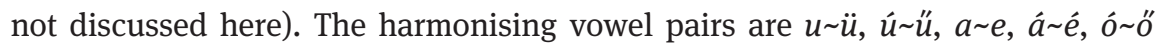
and $o \sim \ddot{o}(\sim e) . i$, $i$ and $e$ are neutral, that is, they can co-occur with both front and back harmonic vowels. As shown in (1), these are exactly the vowels that are headed by the harmonic feature, the element $\mathbf{I}$.

Harmony in Hungarian applies between the last non-neutral stem vowel and any suffix vowel (and it is no longer active stem internally). Alternating suffixes contain a back vowel in their lexical representation, acquiring the element I via spreading when following a harmonic front stem vowel. Vowel harmony can be represented locally as a governing relationship (indicated by an arrow) between nuclei on the Nuclear Projection, where unlicensed nuclei are projected. (The domain final empty nucleus in (2a) and representations below, signalling analytic morphology (indicated by square brackets), is licensed parametrically and is therefore not projected further.) The workings of harmony are illustrated by examples containing the sublative suffix $-r a / r e$. 
(2) (a) tüz+re 'fire subl'

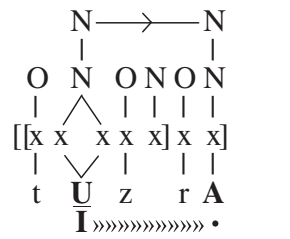

(b) ház+ra 'house suBL'

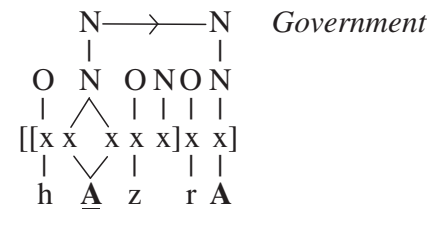

In (2a), the (last and only) front harmonic stem vowel governs the suffix vowel, and as a result, its operator I element spreads to the governed position (indicated by "»»" " on the melodic tier). In (2b), the back harmonic stem vowel also governs the suffix vowel, but as there is no I element to spread, the suffix vowel surfaces in its lexical representation. During multiple suffixation (e.g. tüz + ünk + re 'fire Poss1PL suBL', há $z+u n k+r a$ 'house Poss1PL SUBL'), government and spreading apply iteratively, from the last stem vowel to the first suffix vowel, from the first suffix vowel to the second, etc.

Transparent vowels act as if they were not there, and suffix vowels harmonise with the non-neutral vowel preceding the transparent vowel, as shown by the examples in $(3 a-b)$. However, this cannot be represented as such because skipping transparent vowels would violate the principle of locality. The last stem vowel in $(3 a-b)$ thus governs the suffix vowel as before, but this time it contains the element I as head which therefore should not be able to spread to the suffix vowel.

(a) rövid $+r e$ 'short suBL'

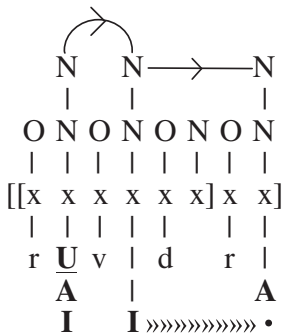

(b) papír $+r a$ 'paper suBL'

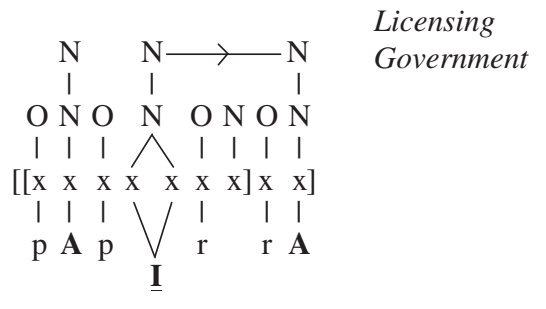

This is indeed correct in (3b) where the neutral vowel is preceded by a back harmonic vowel. In contrast, in (3a), the head $\underline{\mathbf{I}}$, now preceded by a front harmonic vowel, is able to spread. Dienes $(1997,2000)$ proposes that this spreading is licensed by the operator I element in the preceding nuclear position (indicated by a curved arrow above the Nuclear Projection).

Stems containing only neutral vowels are illustrated in (4). Such stems normally take front vowel suffixes. In the case of a monosyllabic stem, as in (4a), the head I is licensed to spread externally, by being in the head position of the word (indicated by a downward pointing arrow). 
(4) (a) víz + re 'water suBL'

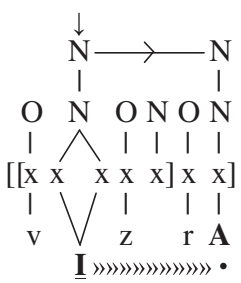

(b) bili + re 'potty SUBL'

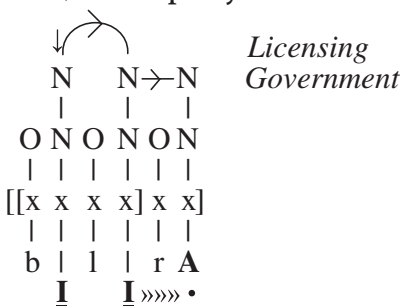

In a polysyllabic stem, as in (4b), the first nucleus is licensed externally, and it is now able to license the second nucleus to spread its head I to the suffix vowel. The closed class of anti-harmonic stems (e.g. hid $+r a$ 'bridge suBL') is marked in the lexicon that they cannot be externally licensed.

Generalising to all types of harmony systems, Dienes (2000) makes the following typological predictions about the behaviour of a neutral vowel headed by the harmonic element $\underline{\mathbf{X}}$ : (i) such a vowel can be harmonic if the element $\underline{\mathbf{X}}$ does not require extra licensing to be able to spread, (ii) it can be transparent if $\mathbf{X}$ may only spread if licensed to do so and (iii) it can be opaque (a non-undergoer and blocker) if $\mathbf{X}$ is not allowed to spread under any circumstances.

Now let us turn to a comparison of the predictions of the two approaches.

\section{Comparison of predictions}

R\&T's predictions are summarised in the table cited in (5), supplemented in the last column with a summary of the predictions of the GP analysis.

(5) Theoretically possible patterns of weak disharmony (stem + suffix) (R\&T ex. (9), p. 11)

\begin{tabular}{|l|c|c|c|c|c|c|}
\hline stem contexts: & {$[\mathrm{B}]_{-}$} & {$[\mathrm{BN}]_{-}$} & {$[\mathrm{N}]_{-}$} & {$[\mathrm{FN}]_{-}$} & {$[\mathrm{F}]_{-}$} & I spreading \\
\hline \multicolumn{7}{|l|}{ attested language types: } \\
\begin{tabular}{|l|c|c|c|c|c|} 
a. opacity, no anti-harmony \\
(E. Khanty)
\end{tabular} & $\mathrm{B}$ & $\mathrm{F}$ & $\mathrm{F}$ & $\mathrm{F}$ & $\mathrm{F}$ & always \\
\hline $\begin{array}{l}\text { b. transparency, no } \\
\text { anti-harmony (Finnish) }\end{array}$ & $\mathrm{B}$ & $\mathrm{B}$ & $\mathrm{F}$ & $\mathrm{F}$ & $\mathrm{F}$ & $\begin{array}{c}\text { I/external } \\
\text { licensing }\end{array}$ \\
\hline $\begin{array}{l}\text { c. transparency, } \\
\text { anti-harmony (Uyghur) }\end{array}$ & $\mathrm{B}$ & $\mathrm{B}$ & $\mathrm{B}$ & $\mathrm{F}$ & $\mathrm{F}$ & I licensing \\
\hline $\begin{array}{c}\text { d. anti-opacity, } \\
\text { anti-harmony (E. Vepsian) }\end{array}$ & $\mathrm{B}$ & $\mathrm{B}$ & $\mathrm{B}$ & $\mathrm{B}$ & $\mathrm{F}$ & never \\
\hline
\end{tabular}




\begin{tabular}{|c|c|c|c|c|c|c|}
\hline stem contexts: & {$[\mathrm{B}]_{-}$} & {$[\mathrm{BN}]_{-}$} & {$[\mathrm{N}]_{-}$} & {$[\mathrm{FN}]_{-}$} & {$[\mathrm{F}]_{-}$} & I spreading \\
\hline \multicolumn{7}{|l|}{ unattested language types: } \\
\hline e. opacity, anti-harmony & B & $\mathrm{F}$ & B & $\mathrm{F}$ & $\mathrm{F}$ & * \\
\hline $\begin{array}{l}\text { f. anti-transparency, no } \\
\text { anti-harmony }\end{array}$ & B & $\mathrm{F}$ & $\mathrm{F}$ & B & $\mathrm{F}$ & * \\
\hline $\begin{array}{l}\text { g. anti-transparency, } \\
\text { anti-harmony }\end{array}$ & B & $\mathrm{F}$ & B & B & $\mathrm{F}$ & * \\
\hline $\begin{array}{l}\text { h. anti-opacity, no } \\
\text { anti-harmony }\end{array}$ & B & B & $\mathrm{F}$ & B & $\mathrm{F}$ & $\begin{array}{l}\text { external } \\
\text { licensing }\end{array}$ \\
\hline
\end{tabular}

In R\&T's account “the well-formed patterns ([5]a-d) are those where the $F$-values and $B$-values are not 'mixed' in their series, i.e. no sequence of $F$ s is interrupted by one or more $B$-values, and no sequence of $B$ s is interrupted by one or more $F$-values" (p. 12).

The GP analysis almost exactly matches R\&T's predictions. When $\underline{\mathbf{I}}$ can spread without extra licence, the vowel is opaque, as in (5a), or rather harmonic, in Dienes's terminology above. (As also noted by R\&T in their fn. 19 (p. 12), these vowels are only neutral in the sense that they can occur in non-alternating suffixes.) In (5b) the vowel is transparent because I requires licensing by an operator I to be able to spread, and there is no anti-harmony because $\mathbf{I}$ is also externally licensed to spread when it occurs in the head position of the word. Type (5c) exhibits transparency together with anti-harmony because $\underline{\mathbf{I}}$ is only licensed to spread by an operator I. In (5d) the vowel is a non-undergoer, a blocker and a non-spreader (i.e. it is completely inert) because I cannot be licensed to spread at all in this type of language. In fact, this is the same kind of behaviour that has been termed "idiosyncratic opacity" in the literature cited above, which can arise if harmony is parasitic on an element that the vowel in question lacks. There are thus two ways to achieve this effect. This vowel seems to behave harmonically, except that it behaves like a vowel in the opposite harmonic class. Types $(5 \mathrm{e}-\mathrm{g})$ are unattested because if $\mathbf{I}$ is allowed to spread without a licence in $[\mathrm{BN}]_{-}$type stems, then it cannot be prevented from spreading in positions where it could be licensed ([N]_ and [FN]_).

The only difference between the two approaches up to this point is presented by (5h), which could be accounted for in GP by allowing I to spread if it is externally licensed, but not if it is licensed by an operator I. This pattern is claimed to be unattested by R\&T and by Kiparsky and Pajusalu (2003), whose article this typology is mostly based on. If this gap is genuine, that means that there is an implicational relationship between the two types of 
licensing: i.e. external licensing is only available if the language also utilises licensing by an operator I. The latter type of licensing is thus unmarked, which is understandable, as the presence of an operator $\mathbf{I}$ is more closely related to harmony than being in the head position of the word. Nevertheless, I also find it possible that the two parameters are independent of each other, and our knowledge of the typology of neutral vowel behaviour in the world's languages is at present simply too limited to be able to make a definite decision on this issue at this point.

The table in (5) only considers cases where the neutral vowel is front. However, this is only a stipulation in R\&T's theory, and for other types of harmony both values would need to be taken into account. In (6) the possibilities for back neutral vowels are presented. The core of the table is the same as in (5), only the labelling changes.

(6) Theoretically possible patterns of weak disharmony for back neutral vowels

\begin{tabular}{|l|c|c|c|c|c|c|}
\hline stem contexts: & {$[\mathrm{B}]_{-}$} & {$[\mathrm{BN}]_{-}$} & {$[\mathrm{N}]_{-}$} & {$[\mathrm{FN}]_{-}$} & {$[\mathrm{F}]_{-}$} & $\mathrm{GP}$ \\
\hline $\begin{array}{l}\text { a. } \text { anti-opacity, } \\
\text { anti-harmony }\end{array}$ & $\mathrm{B}$ & $\mathrm{F}$ & $\mathrm{F}$ & $\mathrm{F}$ & $\mathrm{F}$ & $\star$ \\
\hline $\begin{array}{l}\text { b. transparency, } \\
\text { anti-harmony }\end{array}$ & $\mathrm{B}$ & $\mathrm{B}$ & $\mathrm{F}$ & $\mathrm{F}$ & $\mathrm{F}$ & $\star$ \\
\hline $\begin{array}{l}\text { c. transparency, no } \\
\text { anti-harmony }\end{array}$ & $\mathrm{B}$ & $\mathrm{B}$ & $\mathrm{B}$ & $\mathrm{F}$ & $\mathrm{F}$ & empty \\
\hline $\begin{array}{l}\text { d. opacity, no } \\
\text { anti-harmony (Seto) }\end{array}$ & $\mathrm{B}$ & $\mathrm{B}$ & $\mathrm{B}$ & $\mathrm{B}$ & $\mathrm{F}$ & incompatible \\
\hline $\begin{array}{l}\text { e. anti-opacity, } \\
\text { no anti-harmony }\end{array}$ & $\mathrm{B}$ & $\mathrm{F}$ & $\mathrm{B}$ & $\mathrm{F}$ & $\mathrm{F}$ & * \\
\hline $\begin{array}{l}\text { f. } \text { anti-transparency, } \\
\text { anti-harmony }\end{array}$ & $\mathrm{B}$ & $\mathrm{F}$ & $\mathrm{F}$ & $\mathrm{B}$ & $\mathrm{F}$ & * \\
\hline $\begin{array}{l}\text { g. anti-transparency, } \\
\text { no anti-harmony }\end{array}$ & $\mathrm{B}$ & $\mathrm{F}$ & $\mathrm{B}$ & $\mathrm{B}$ & $\mathrm{F}$ & * \\
\hline h. opacity,anti-harmony & $\mathrm{B}$ & $\mathrm{B}$ & $\mathrm{F}$ & $\mathrm{B}$ & $\mathrm{F}$ & $\star$ \\
\hline
\end{tabular}

R\&T predict the same four systems as for front neutral vowels. In GP, (6a-b) and $(6 \mathrm{e}-\mathrm{h})$ are excluded because a back neutral vowel possesses no element I which could harmonise (in contexts $[\mathrm{BN}]_{-}$and $[\mathrm{N}] \_$). Type (6c) can be regarded as a case of "idiosyncratic transparency", where a vowel is invisible to harmony because it is melodically completely empty. Type (6d) is the case of expected 
opacity, caused by the vowel's incompatibility with the harmonic feature. This is not a common type of pattern in palatal harmony (for a possible explanation of which, see Polgárdi 1998), but Kiparsky and Pajusalu (2003) mention the Seto dialect of Estonian, where $[\varnothing]$ is prohibited from non-initial syllables, resulting in contextual neutralisation, and therefore [o] is opaque. According to them, opacity is the only possible behaviour for back neutral vowels. I do not know of any concrete examples of the pattern in (6c), but as this is regarded as an exceptional pattern in GP, I do not consider this problematic. R\&T's approach, however, overgenerates in $(6 a-b)$.

Constant patterns, where all stem contexts are assigned the same value ( $F$ or $B$ ) are excluded by $R \& T$ by requiring matching values in prototypical contexts (B in $[\mathrm{B}]_{-}$and $\mathrm{F}$ in $[\mathrm{F}]_{-}$), called the Proper prototypical values assumption (ex. (24), p. 22). Without satisfying this requirement, the language cannot exhibit harmony. In the constant patterns, there is a phonotactic restriction on suffix vowel quality, regardless of the quality of stem vowels. GP also predicts the non-existence of these patterns as cases of harmony: an all front pattern is impossible because back vowels have no I element to spread; while in an all back pattern, I does not spread at all, i.e. there is no harmony, only a phonotactic restriction excluding front vowels from occurring in suffixes.

Apart from the stable patterns reviewed so far, R\&T also examine possible patterns of variation. They predict that "variation between two values can only occur in a context or a contiguous sequence of contexts that is at the border of contexts which are assigned non-identical values" (p. 37). This means the three columns $[\mathrm{BN}]_{-},[\mathrm{N}]_{-}$and $[\mathrm{FN}]_{-}$in (5) and (6). In GP, variation in (5) can be accounted for by optionality in the different types of licensing discussed above. In the context $[\mathrm{FN}]_{-}$, spreading of $\mathbf{I}$ is optionally licensed by an operator $\mathbf{I}$; in the context $[\mathrm{N}]_{-}$, it is optionally licensed externally; and in $[\mathrm{BN}]_{-}$, I may optionally spread without a licence. Again, the question of independence between the parameters of the two types of licensing arises. Optionality can also mean lexical variation, similarly to R\&T's account, as in the case of Hungarian anti-harmony discussed above. The Polysyllabic Split in anti-harmony and the Count Effect in transparency in Hungarian can be accounted for by allowing for optional licensing of $\underline{I}$ to spread by a preceding head $\underline{\mathbf{I}}$. In (6), in contrast, variation is not predicted by GP as there is no active agent that could apply optionally (whereas R\&T predict the same types of variation as found in (5)).

Finally, because of the proper prototypical values requirement, R\&T predict that cases of optional harmony should be non-existent. In my view, this prediction might be too strong. If, however, this requirement is relaxed, then no difference can be made between the two extreme points of the scale and variation in both contexts, $[\mathrm{B}]_{-}$and $[\mathrm{F}]_{-}$, is expected. In contrast, GP only 
predicts potential variation in $[\mathrm{F}]_{-}$because context $[\mathrm{B}]_{-}$does not contain the harmonic feature and, therefore, nothing can spread here. Although I do not know of a language fully exhibiting this pattern of harmony, a partial example found in Finnish suggests that this possibility is a plausible one. Ringen and Heinämäki (1999) examine disharmonic roots in Finnish and find that when the last harmonic root vowel is back, a back suffix vowel is chosen without variation, whereas there is variation when the last harmonic root vowel is front.

\section{Summary}

All in all, the predictions of the two proposals are not radically different. The GP approach is on the whole somewhat more restrictive, except for the case of (5h) and the case of optional harmony. As far as I see, the representational approach shows a closer fit with available data, although our knowledge about the details of the typology is still rather fragile. And, of course, the two approaches are not inherently incompatible, and perhaps both could benefit from a combination.

\section{References}

Demirdache, Hamida. 1988. Transparent vowels. In H. van der Hulst \& N. Smith (eds.), Features, segmental structure and harmony processes. Part II, 39-76. Dordrecht: Foris.

Dienes, Péter. 1997. Hungarian neutral vowels. The Odd Yearbook 1997, 151-180. http:// budling.nytud.hu/ cash/odd/ (accessed 30 March 2015).

Dienes, Péter. 2000. Hungarian transparent vowels. An account of Hungarian palatal harmony in terms of Government Phonology. Budapest: ELTE MA thesis.

Harris, John. 1994. English sound structure. Oxford: Blackwell.

Hulst, Harry van der. 1988. The geometry of vocalic features. In H. van der Hulst \& N. Smith (eds.), Features, segmental structure and harmony processes. Part II, 77-126. Dordrecht: Foris.

Hulst, Harry van der \& Norval Smith. 1986. On neutral vowels. In K. Bogers, H. van der Hulst \& M. Mous (eds.), The phonological representation of suprasegmentals, 233-279.

Dordrecht: Foris.

Kaye, Jonathan. 1990. 'Coda' licensing. Phonology 7. 301-330.

Kaye, Jonathan, Jean Lowenstamm \& Jean-Roger Vergnaud. 1985. The internal structure of phonological elements: A theory of Charm and Government. Phonology Yearbook 2. 305-328.

Kaye, Jonathan, Jean Lowenstamm \& Jean-Roger Vergnaud. 1990. Constituent structure and government in phonology. Phonology 7. 193-231.

Kiparsky, Paul \& Karl Pajusalu. 2003. Towards a typology of disharmony. The Linguistic Review 20. 217-241.

Polgárdi, Krisztina. 1998. Vowel Harmony. An account in terms of Government and Optimality. The Hague: Holland Academic Graphics.

Ringen, Catherine O. \& Orvokki Heinämäki. 1999. Variation in Finnish vowel harmony: An OT account. Natural Language and Linguistic Theory 17. 303-337. 